\title{
Temperature Regulations during the Transport of Perishables in Australia
}

\author{
Estrada-Flores, S., Smale. N and Tanner, D.J. \\ E-mail: Silvia.Estrada-Flores@csiro.au \\ Food Science Australia. P.O. Box 52, North Ryde. NSW, 1670 Australia
}

\begin{abstract}
National guidelines and regulations provide recommendations on the maximum and minimum food temperatures that should be expected during transport. However, in routine logistics operations temperature variations occur due to logistic constraints or performance issues. This paper discusses the Australian temperature-based regulations, using two case studies to illustrate the application of these regulations on real temperature history scenarios in road and sea freight. The first study refers to the urban distribution of chilled groceries using delivery vehicles. This study integrates a mathematical model for the growth of spoilage organisms to show the anticipated impact of temperature variability on product quality. The second case refers to a frozen export shipment which malfunctioned before arrival. An interpretation of the product temperature variability observed after the failure is made in terms of the likely consequences in product quality. The study concludes that there is a need to harmonize existing private and public regulations regarding transport of perishable products. This is especially important for the Australian export industry where such harmonization encompasses international trade regulations and requirements.
\end{abstract}

Keywords: Australia, regulation, temperature, food, transport

\section{Introduction}

Australia was listed as one of the twenty major food trading countries, with nearly $\$ 18$ billion USD in food exports during 2004/2005 and a domestic (retail) business of \$ 67.5 billion USD in the same period (DAFF, 2005). About $95 \%$ of the food exports are shipped via maritime transport. Voyage times from Australia to key markets in the Northern Hemisphere range from 7 days from Western Australia to Singapore, up to 40 days from Melbourne to the United Kingdom. Technical challenges during maritime transport include the fact that refrigerated containers have a relatively large surface area to volume ratio and air distribution inside the container is not always optimal (Tanner and Amos, 2003). Containers are therefore prone to substantial temperature variability, if mechanical and operational factors are not optimised.

In terms of road transportation in Australia, the geographic and climatic extremes across the country impose particular pressures on mobile transport equipment to perform. A report prepared by ACIL Tasman (2004) states that Australia has unusually high freight levels and road length per capita, compared to other countries in the world, due to its relatively small population and vast area of the country. Trucks provide nearly all domestic freight transport and are the only mode available in many country areas. Air freight is used for food products that have a high export value, predominantly to Hong Kong, Japan and Singapore, although airfreighted exports declined 25\% in 2005 from a peak in 2001 (DAFF, 2005).

Other challenges in domestic and export operations refer to logistic constraints, such as transient periods in which the product may be under non-controlled temperature conditions (eg. pallets of product being left out of refrigerated storage before loading, door openings 
during urban distribution, etc). The effect of these sporadic temperature excursions on the growth of microorganisms that represent a health risk are a concern for policy makers, which have attempted to regulate the transport of perishable products by ruling on "maximum" and "minimum" temperatures. However, no distinctions are made regarding the type of product transported and the length of exposure to temperatures above the maximum limit, even though the product composition and the exposure time are crucial factors in the development of spoilage micro-organisms.

The delivery of high quality products to local and overseas markets is imperative for the growth of Australasian perishable commodity industries. In the context of this paper, the term 'quality' must be understood as the combination of the sensory state and the microbiological state of the product. This distinction is important, given that for some products and under particular circumstances, microbial risks can develop without obvious signs of organoleptic spoilage. For example, growth and toxin production of $C$. botulinum in vacuum packed and modified atmosphere packed whiting fillets stored below $8{ }^{\circ} \mathrm{C}$ has been proven to occur well before evident signs of spoilage are detected (Post et al., 1985).

This paper discusses the regulatory environment that Australian logistics operators need to consider when shipping perishable products. Over the past years, Food Science Australia have undertaken intensive studies of product temperature variability within transport systems, including refrigerated trucks, refrigerated containers and vessels. These studies were made to ascertain how equipment design, loading and/or operation affect product temperature stability and quality. Two case studies will be presented to showcase the results of monitoring domestic and export refrigerated transport systems: (a) the urban transport of perishables in a refrigerated panel van and (b) the export of frozen fish in a container that malfunctioned before arrival. These case studies integrated product temperature histories with predictive models to assess the effect of temperature variability. The results are discussed in the context of the current Australian regulations for refrigerated transport.

\section{Australian Food Safety Regulatory System}

The public food safety regulatory system for Australia has three essential components (Martin et al., 2003):

(1) National food safety standards (eg. the Food Code; FSANZ, 2006)

(2) State and Territory Food Acts

(3) Supporting infrastructure projects, such as guidelines for temperature and microbial safety requirements (FSANZ, 2001, 2002).

Private regulation, in the form of self-regulation for the safe transport of food products has two main embodiments:

(4) The Australian Cold Chain Guidelines (Anon., 1999)

(5) The Australian Standard 4982-2003 (Committee ME-006, 2003)

Explanations of these five categories are presented below.

\section{The Australia New Zealand Food Standards Code}

The Australia New Zealand (ANZ) food standards system is a co-operative arrangement between Australia, New Zealand and the Australian States and mainland Territories to develop and implement uniform food standards. Food transportation is dealt with by the ANZ Food Standards Code (2002) as a general item in the Section "Food Handling Controls". Section 3.2.2 states:

"A food business must, when transporting food: 
(a) protect all food from the likelihood of contamination;

(b) transport potentially hazardous food under temperature control; and

(c) ensure that potentially hazardous food which is intended to be transported frozen remains frozen during transportation."

Where "temperature control" is defined as the maintenance of food at a temperature of:

(i) $5{ }^{\circ} \mathrm{C}$, or below if this is necessary to minimize the growth of infectious or toxigenic micro-organisms in the food, so that the microbiological safety of the food will not be adversely affected for the time the food is at that temperature; or

(ii) $60{ }^{\circ} \mathrm{C}$ or above; or

(iii) other temperature, if the food business demonstrates that maintenance of the food at this temperature for the period of time for which it will be so maintained, will not adversely affect the microbiological safety of the food".

In part (iii), no remark regarding what actually constitutes a valid demonstration for the use of temperatures other than the $5{ }^{\circ} \mathrm{C}$ guideline is made. The methods and procedures required to effectively follow product temperatures during transport are also not specified.

\section{State and Territory Food Acts}

State and Territory Health or Human Services Departments are responsible for enforcement of the Food (or Health) Acts. In an effort to increase uniformity of food safety standards in Australia, States and Territories amended their legislation to adopt the food safety standards in 2002. Under these amendments, all food transporters in Australia need to comply with the obligations stated in 2.1. Receivers of food may require food transporters to provide evidence of transport times and temperatures. However, chilled products do not necessarily have to be transported in refrigerated vehicles; other means to keep foods chilled during transport (including using insulation, gel packs, eskies and ice bricks) are accepted as reasonable control measures.

\section{Guidelines for temperature requirements}

The guideline entitled "Temperature control of potentially hazardous foods" has been developed by FSANZ to help food businesses understand and comply with the requirements to keep food under temperature control, as stated in section 2.1. The guide, unlike the Food Safety Standards, is not legally binding. In this guide, the minimum accuracy of temperature measurement instruments is established as $\pm 1^{\circ} \mathrm{C}$. As a means to account for the time factor on the development of harmful bacteria during preparation, storage, transport and display, the guideline establishes the so-called $2 \mathrm{hr} / 4 \mathrm{hr}$ rule:

- If $\mathrm{T}_{\text {food }}>5^{\circ} \mathrm{C}$ and $\mathrm{T}_{\text {food }}<60^{\circ} \mathrm{C}$ for $t<2 \mathrm{hrs}$, the product needs to be returned to refrigeration temperatures for final use later or ensure it is used before $4 \mathrm{hrs}$.

- If $\mathrm{T}_{\text {food }}>5^{\circ} \mathrm{C}$ and $\mathrm{T}_{\text {food }}<60^{\circ} \mathrm{C}$ for $2 \mathrm{hrs}<t<4 \mathrm{hrs}$, the product needs to be used within 4 hrs.

- If $\mathrm{T}_{\text {food }}>5^{\circ} \mathrm{C}$ and $\mathrm{T}_{\text {food }}<60^{\circ} \mathrm{C}$ for $t>=4 \mathrm{hrs}$, the product needs to be discarded

\section{The Australian Cold Chain Guidelines}

The Australian Cold Chain Guidelines, a self-regulatory measure introduced by the Australian Food and Grocery Council (AFGC), the Australian Supermarket Institute (ASI), the Refrigerated Warehouse and Transport Association (RWTA) and private companies in the retail and distribution sectors, provide recommendations for the safe transport of perishable products. These specify the following temperature requirements for the transport of frozen foods and chilled foods for retail sale and food service outlets: 
- $\quad$ For chilled products, the air temperature should remain between $0{ }^{\circ} \mathrm{C}$ and $4{ }^{\circ} \mathrm{C}$, to ensure that the product is never warmer than $5^{\circ} \mathrm{C}$

- $\quad$ Frozen products should be handled never warmer than $-18^{\circ} \mathrm{C}$

No specific references to short temperature excursions above the $5{ }^{\circ} \mathrm{C}$ guideline are made. Nevertheless, variations to the "never warmer" statement are allowed for some varieties of fish and shellfish (which require temperatures below $5{ }^{\circ} \mathrm{C}$ ) or for cured meats such as prosciutto and salami-style products, which may keep their quality at temperatures above $5{ }^{\circ} \mathrm{C}$. The supplier and customer can establish the specific transport to be used, always having in mind the final objective of quality and safety. The guidelines also contain generic HACCP Food Safety Programs for food handling businesses.

\section{The Australian Standard 4982-2003}

This standard covers key performance tests that provide information about the insulation effectiveness and the performance of the cooling plant of refrigerated transport equipment. It follows closely the ATP Agreement in Europe for the transport of perishables and the ISO standard 1496-2:1996(E) for freight containers. Nevertheless, compliance with the Australian standard is voluntary. This standard does not provide any means to measure temperature variability within the cargo space. Therefore, the AS 4982-2003 is less effective than the Australian Cold Chain Guidelines and the ANZ Food Code in providing a clear link between keeping product quality and refrigerated truck performance.

\section{Compliance of shipments with regulations}

Ideally, the transport of perishables should be performed under conditions that extend the good agricultural practices, the good manufacturing practices and the hazard control plans used at different stages of the commercial chain (IFT, 2001). However, there are interrelated practical, technical and regulatory factors influencing the temperature management practices during the transport of foods (Estrada-Flores, 2003). These issues are illustrated in the case studies presented in this section for short duration truck delivery and container transport for export shipments.

\section{Case study 1: Urban Transport of chilled groceries}

Urban refrigerated transport is characterized by the use of small vans with more frequent, though shorter-lived, temperature variations than seen in trucks used in long distance distribution. The typical working schedule for these vans usually includes warming of the product during loading into the van (due to the design of facilities used) and several door openings to deliver the parcels. These factors commonly lead to a loss of temperature control, particularly in the summer.

Estrada-Flores and Tanner (2005) investigated the spoilage risks during the urban delivery of chilled food products. Measured temperature histories were integrated with respect to mathematical models to predict growth of pseudomonads. The experimental tests were conducted inside a testing facility at $+30{ }^{\circ} \mathrm{C}$ and a relative humidity of $80 \%$, which reflect common ambient conditions found in coastal cities in Australia during summer. A threecompartment van was loaded with plastic bins containing assorted perishable goods. The chiller compartment was loaded with twenty bins, previously stored in a coolroom to ensure an initial product temperature of $3{ }^{\circ} \mathrm{C}$. An individual data logger (Tinytag ${ }^{\mathrm{TM}}$ Gemini Data Loggers, UK, 12 bit internal sensor, range -40 to $85^{\circ} \mathrm{C}$, accuracy $\pm 0.2^{\circ} \mathrm{C}$ ) was placed within each bin, inside one of the bags containing the chilled products. The van was fully loaded 
prior to commencement of the delivery schedule and the total transportation time was $4 \mathrm{hrs}$. The simulated delivery schedule encompassed twenty door openings, during which time one bin was removed from the chiller compartment, alongside other bins from the freezer and grocery compartments. Temperature histories were obtained and the data collected from the bins transporting chilled product in both trials was integrated with respect to the following model that describes the relationship between temperature and the rate of aerobic growth of pseudomonads (Ross, 1999):

$$
\sqrt{k_{\text {pseudomonads }}}=0.0363 \bullet(T+7.7) \bullet\left[1-e^{0.192 \bullet(T-41)}\right],-1.5^{\circ} \mathrm{C} \geq \mathrm{T} \geq 38{ }^{\circ} \mathrm{C} \quad \text { Eqn. (1) }
$$

Where $k_{\text {pseudomonads }}$ is the generation rate for pseudomonads $\left(\mathrm{gen} \cdot \mathrm{hr}^{-1}\right)$ and $T\left({ }^{\circ} \mathrm{C}\right)$ is the bin temperature. The total number of generations (TNG, gen) was estimated for each temperature history by using Eq.(2):

$$
T N G=\sum_{i=1}^{n} \Delta t \bullet k \text { at } t=i
$$

Where $n=240$ and $\Delta t$ is the time interval between temperature readings.

Figure 1 (a) shows the twenty product temperatures measured during the trial. Only $30 \%$ of the product temperatures measured during the $4-\mathrm{hr}$ trial were below $5{ }^{\circ} \mathrm{C}$, which is the maximum limit established in the Australian Cold Chain Guidelines and the ANZ Food Code. In general, a quick warming of the products during loading was observed and chilled product that stayed in the vehicle the longest remained warm, due to the low cooling capacity of the vans used. Figure 1 (b) shows that all bins presented favourable growth temperatures for pseudomonads. However, the growth of pseudomonads was well below the spoilage limit (less than 1 generation). Therefore, it was concluded that the sporadic and short-lived temperature excursions during the simulated distribution schedule hereby described had minimal consequences on the spoilage rate of products. These results agree with the recommendations of some Australian states (eg. Food Safety Unit Department of Human Services, 2005), for the home delivery of food by supermarkets and other food-related businesses, that state a total delivery time recommended is $4 \mathrm{hrs}$, including 30 mins of nonrefrigerated transport conditions. The results of this study highlighted the need to adopt more sophisticated monitoring approaches, such as time-temperature indicators. The use of temperature histories integrated to models that describe the dynamic behaviour of spoilage and pathogenic bacteria may enable a more holistic approach to assess the quality of foods. 

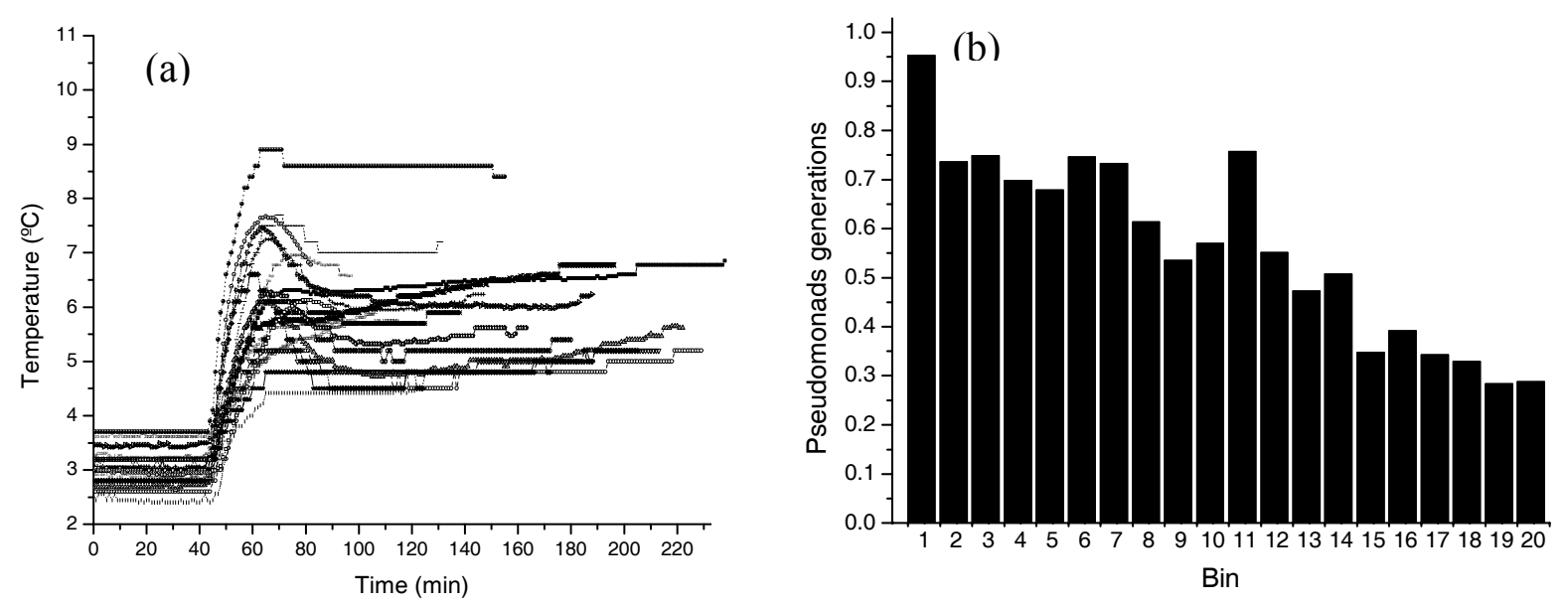

Figure 1: (a) Monitored temperature of the 20 bins of chilled product during the simulated transport trial and (b) pseudomonads generations predicted in each bin during the 4hr trial.

\section{Case study 2: Export shipping of frozen fish in containers}

The transport of frozen goods has been traditionally perceived as a less technically demanding task than the transport of respiring, chilled product. No serious quality or safety issues have been associated with subtle losses of temperature control, as long as product temperatures remain below $-18{ }^{\circ} \mathrm{C}$. However, more significant quality losses can occur when product temperatures increase to above $-12{ }^{\circ} \mathrm{C}$ in frozen shipments. The difference between -18 and $-12{ }^{\circ} \mathrm{C}$ (ie. $6{ }^{\circ} \mathrm{C}$ ) is known as the "buffer zone", in which frozen products are still considered to be in a safe temperature zone. Some detrimental effects in quality are unpleasant smells, stained packaging or large ice crystals around the product after transport (Estrada-Flores, 2005).

This case study investigated the variability in temperature distributions throughout a 20' container load of frozen fish. The container was loaded with approximately 700 blocks of frozen fish (whole) wrapped in plastic bags, with an initial temperature of $-19{ }^{\circ} \mathrm{C}$. Ninety Tinytag ${ }^{\mathrm{TM}}$ dataloggers $\left(12\right.$ Bit internal sensor, Range $\mathrm{G},-40$ to $+85^{\circ} \mathrm{C}, \pm 0.2{ }^{\circ} \mathrm{C}$, Gemini Data Loggers, UK) were placed in direct contact with the blocks of frozen fish, thus the temperatures measured represented the dynamics of the product surface. The dataloggers were strategically placed to represent the temperature variability in all spatial dimensions of the load. The container left from the Port of Singapore to Sydney, Australia, arriving 20 days after loading.

As a result of a failure in the refrigeration plant of the container, the internal temperature (initially at $-22{ }^{\circ} \mathrm{C}$ ) increased rapidly and product warming occurred after approximately 2.5 days of loading (Fig. 2). All product presented temperature above the "buffer zone" after 15 days of voyage. 


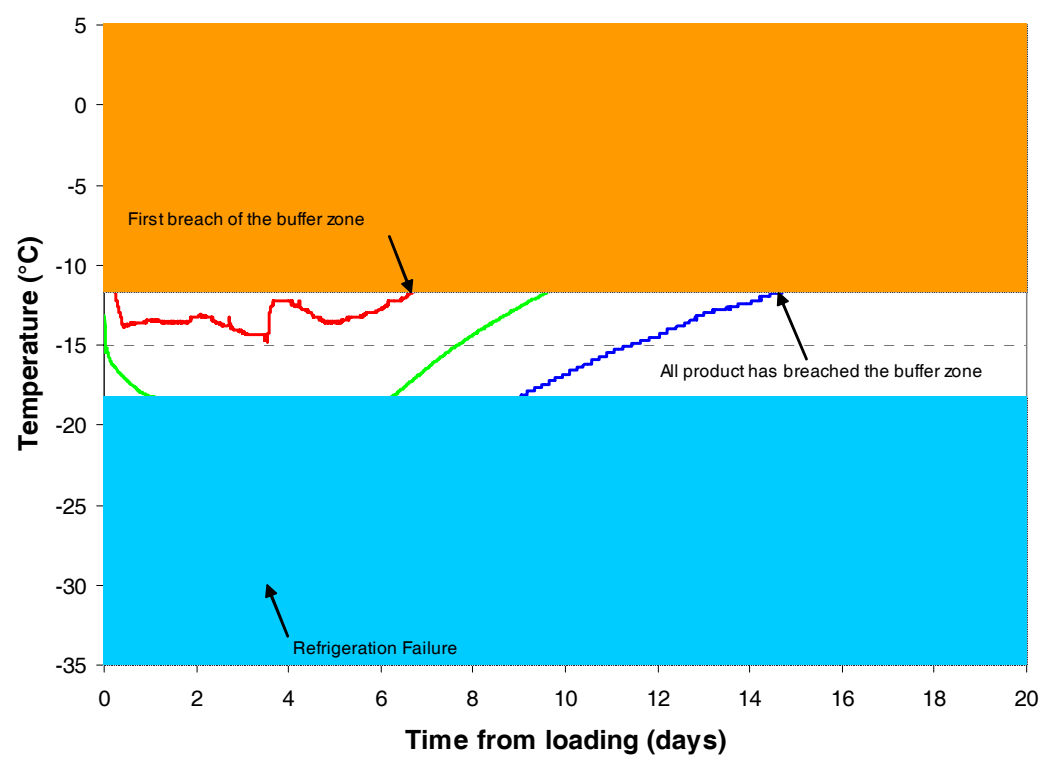

Figure 2: Maximum (-), average $(-)$ and minimum $(-)$ product temperatures measured during the 20-day shipping trial.

Only $18 \%$ of the temperatures measured fulfilled the "never warmer than $-18{ }^{\circ} \mathrm{C}$ " established in the Australian Cold Chain Guidelines 1999, as shown in Figure 3. In terms of microbial growth, all temperatures remained below the minimum growth temperature of the majority of micro-organisms, with the exception of Yersinia enterocolitica and Listeria monocytogenes, which have been reported to grow at -1.3 and $-0.4{ }^{\circ} \mathrm{C}$, respectively. However, Fig. 3 suggests that at least $10 \%$ of the product was partially defrosted when it arrived in Sydney. A visual inspection showed that water from the thawed fish portions had leaked from several bags, therefore increasing the spoilage risks due to the increased availability of free water supporting microbial growth and the contamination of other bags.

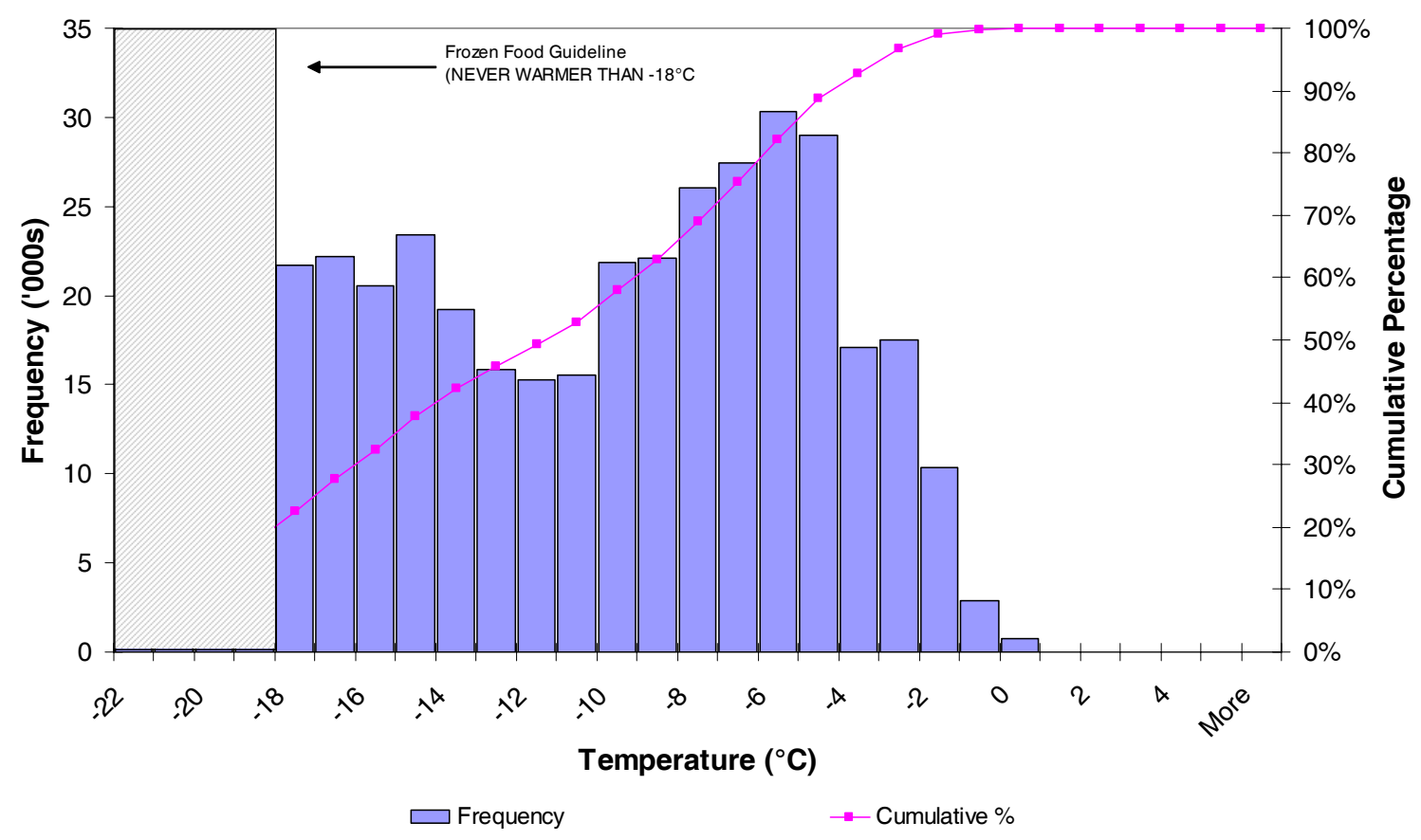

Figure 3: Frequency distribution chart of the fish temperatures during the 20-day shipping trial, showing the "never warmer than $-18{ }^{\circ} \mathrm{C}$ " rule 
Another detrimental effect in this case would be the loss of shelf-life as a result of increased enzymatic activity (eg. rancidity). Transient situations leading to loss of temperature control (e.g. defrost, temporary loss of refrigeration power, loading and unloading operations between transport modes and/or between coldstorage and sudden change of external environmental conditions, amongst others) are unavoidable during sea transport of frozen products. The impact of these factors can be minimised by: (a) ensuring that the refrigerated transport is operating optimally, (b) selecting a route that does not compromise the integrity of the product, (c) providing training to staff involved in the logistic operations, (d) selecting adequate packaging, (e) communicating in a continuous manner with the carriers and (f) designing contingency plans to implement when faced with undesirable scenarios that may compromise the quality of the frozen cargo.

\section{Conclusions}

The case studies presented here highlight the multifactorial nature of food quality and the need to broaden the scope of current regulations into more sophisticated quality control approaches. One possibility is the adoption of time-temperature indicators; the use of temperature histories integrated to models that describe the dynamic behaviour of spoilage and pathogenic bacteria may enable a more holistic approach to assess the quality of foods.

There is a scarcity of information regarding systematic risk assessments of temperature abuse during transport in Australia and its relative significance in the context of the whole cold chain. This limits the scope of regulatory bodies and associations, which rely on enforcing temperatures, deemed to be safe for storage conditions, rather than specific transport guidelines for products. Compliance with national thermal performance standards for refrigerated equipment is often perceived as a bureaucratic exercise by companies engaged in logistics of perishable products. Particularly if they are already complying with the temperature specifications demanded by the retail industry and the existing Codes of Practices. To avoid this perception, there is a need to harmonize the existing private and public regulations regarding transport of perishable products, thus avoiding repetition and increasing congruence in the regulatory framework. This is especially important for the Australian export industry when such harmonization encompasses international trade regulations and requirements.

\section{Literature Cited}

ACIL Tasman. 2004. Trucking - Driving Australia's Growth and Prosperity. A report prepared for the Australian Trucking Association. 26 pp.

Anon, 1999. The Australian Cold Chain Guidelines: For the handling, storage and transport of frozen foods, ice cream and chilled foods for retail sale and in food service outlets. Published by the Australian Food and Grocery Council (AFGC), the Australian Supermarket Institute (ASI), the Refrigerated Warehouse and Transport Association (RWTA). 39 pp.

Australian Government Department of Agriculture, Fisheries and Forestry. Australian Food Statistics 2005. Commonwealth of Australia. 174 pp.

Committee ME-006. AS 4982-2003. Thermal performance of refrigerated transport equipment -Specification and testing. Australian Standard. Standards Australia. (2003) 54 pp 
Estrada-Flores, S. 2003. Safe temperature regulations during the road transport of fresh cuts. Proc. Int. Cong. Refrig. ICR 0621. 8 pp.

Estrada-Flores,S. 2005. Transportation of frozen foods. In: Sun, D.W. (Ed). Handbook of Frozen Food Processing and Packaging.CRC Press. pp. 227-242

Estrada-Flores, S. and Tanner, D. 2005. Temperature variability and prediction of food spoilage during urban delivery of food products. ISHS Acta Horticulturae 674: 63-69. III International Symposium on Applications of Modelling as an Innovative Technology in the Agri-Food Chain; MODEL-IT.

Food Standards Australia New Zealand. 2001. User Guide to Standard 1.6.1 Microbiological limits for food with additional guideline criteria. In: Australia New Zealand Food Standards Code (incorporating Amendment 38). Anstat Pty Ltd. 22 pp.

Food Standards Australia New Zealand.2006. Australia New Zealand Food Standards Code. Unofficial consolidated version incorporating amendments up to and including Amendment 86. Commonwealth of Australia.

Food Standards Australia New Zealand. 2002. Food Safety: temperature control of potentially hazardous foods. Canberra. 9. Commonwealth of Australia. 19 pp.

Food Safety Unit Department of Human Services Melbourne Victoria. 2005. Guideline for the un-refrigerated delivery of perishable foods. State of Victoria, Department of Human Services. 2 pp. From the website:

http://www.health.vic.gov.au/foodsafety/downloads/unrefrig_jan05.pdf

Institute of Food Technologists. 2001. Analysis and evaluation of preventive control measures for the control and reduction/elimination of microbial hazards on fresh and fresh-cut produce. Beuchat LR, Busta FF, Farber JM, Eds

Martin, T., Dean, E., Hardy, B., Johnson, T., Jolly, F., Mathews, F., McKay, I., Souness, R., \& Williams, J. 2003. A new era for food safety regulation in Australia. Food Control. 14: $429-438$.

Post, L.S., D.A. Lee, M. Solberg, D. Furgang, J. Specchio and C. Graham. 1985. Development of botulinal toxin and sensory deterioration during storage of vacuum and modified atmosphere packaged fish fillets. J. Food Sci. 50:990-996.

Ross, T. 1999. Predictive Food Microbiology Models in the Meat Industry. Meat and Livestock Australia (MLA). July 1999.

Standards Australia. AS 4982-2003. Thermal performance of refrigerated transport equipment -Specification and testing. (2003) 54 pp.

Tanner, D.J. and Amos, N.D. (2003). Modelling product quality changes as a result of temperature variability in shipping systems. Proc. Int. Congr. Refrig. Paper 243. 